\title{
Opiniões de Professores sobre um Curso de Formação Profissional Presencial com Emprego de Multimídias: lições aprendidas por meio da avaliação externa
}

\author{
CLAUDIA DAVIS \\ Pesquisadora da Fundação Carlos Chagas; Professora do Programa de Estudos \\ Pós-Graduados em Psicologia da Educação da PUC-SP \\ cdavis@fcc.org.br \\ YARA LÚCIA ESPOSITO \\ Pesquisadora da Fundação Carlos Chagas \\ yesposito@fcc.org.br \\ MARINA MUNIZ ROSSA NUNES \\ Pesquisadora da Fundação Carlos Chagas \\ Orientadora Educacional do Colégio Santa Cruz \\ mnunes@fcc.org.br \\ CESAR AUGUSTO DO AMARAL NUNES \\ Diretor da OORT Tecnologia e Pesquisador da Escola do Futuro da USP-SP \\ cnunes@futuro.usp.br
}

\begin{abstract}
Resumo
Este trabalho tem como objetivo descrever a avaliação feita por professores do ensino fundamental (com habilitação em nível médio) acerca de um curso de formação superior, em nível de licenciatura, até então inédito no país. O Programa de Educação Continuada/Formação Universitária (PEC/FU1) foi desenvolvido de modo presencial, utilizando diferentes mídias interativas: videoconferências, teleconferências, trabalho monitorado, vivências educadoras e oficinas culturais. Para avaliar a opinião dos alunos sobre o curso, uma série de estudos foi realizada. Descrevem-se, aqui, apenas os resultados obtidos por meio de dois opinionários, compostos de questões fechadas, sobre a relação que os alunos-professores estabeleceram entre sua participação no Programa, a ocorrência de melhorias substanciais em sua formação profissional e mudanças em suas práticas pedagógicas em sala de aula. Esse instrumento, respondido on-line, foi aplicado duas vezes: no início e ao final do Programa. Os dados receberam vários processamentos estatísticos para que se pudesse obter uma síntese das informações, identificando eventuais diferenças de opiniões em relação aos aspectos investigados por local de estudo e por universidade. Os

1 A Fundação Vanzolini, em contrato com a Fundação para o Desenvolvimento da Educação (FDE), gerenciou todo o processo de elaboração, implementação e avaliação desse Programa.
\end{abstract}


resultados mostraram que os principais benefícios advindos do Programa foram, de acordo com os professores, a oportunidade de reflexão a respeito da profissão docente, a fundamentação teórica adquirida e a maior compreensão do processo de ensinoaprendizagem. Críticas foram também tecidas, em especial no que concerne ao tempo disponível que os discentes que acumulavam dupla jornada de trabalho tinham para leituras e estudos; ao insuficiente preparo do tutor para orientá-los; e à complexidade dos textos escritos, que dificultava a compreensão dos temas abordados. Aprimorar esses aspectos parece ser necessário para que os objetivos traçados possam ser alcançados, atendendo-se, sobretudo, às expectativas criadas.

Palavras-chave: formação superior, avaliação de curso, mídias interativas.

\title{
Resumen
}

Este trabajo tiene como objetivo describir la evaluación que los profesores de enseñanza fundamental (con habilitación en nivel medio) hicieron acerca de un curso de formación superior (en el nivel de licenciatura) inédito en el país hasta ese momento. El Programa de Educación Permanente/Formación Universitaria (PEC/FU) fue desarrollado de modo presencial, utilizando diferentes medios interactivos: videoconferencias, teleconferencias, trabajo monitoreado, vivencias educativas y talleres culturales. Para evaluar la opinión de los alumnos sobre el curso se realizaron una serie de estudios. Aquí se describen solamente los resultados obtenidos por medio de dos cuestionarios de opinión compuestos de cuestiones cerradas, sobre la relación que los alumnos-profesores establecieron entre su participación en el programa, las mejoras sustanciales en su formación profesional y los cambios en sus prácticas pedagógicas en el aula. Este instrumento, respondido on-line, se aplicó dos veces: al comienzo y al final del Programa. Los datos recibieron varios procesamientos estatísticos para poder obtener una síntesis de las informaciones, identificando eventuales diferencias de opiniones en relación a los aspectos investigados por local de estudio y por universidad. Los resultados mostraron que los principales beneficios derivados del Programa fueron, según los profesores, la oportunidad de reflexionar acerca de la profesión docente, la fundamentación teórica adquirida y una mayor comprensión del proceso de enseñanza-aprendizaje. Se formularon también algunas críticas, especialmente en lo que se refiere al tiempo disponible para leer y estudiar (debido a la doble jornada de trabajo de algunos estudiantes), a la preparación insuficiente del tutor para orientarlos y a la complejidad de los textos escritos que dificultaba la comprensión de los temas abordados. Mejorar estos aspectos parece necesario para alcanzar los objetivos trazados, atendiendo especialmente a las expectativas creadas.

Palabras-clave: formación superior, evaluación del curso, medios interactivos.

\begin{abstract}
This paper will describe the evaluation elementary school teachers (with a secondary school degree) made of a higher education course, at a licensure level, which was as yet new in the country. The Program of Continuing Education/Higher Education was developed as a classroom course, using different interactive media: videoconferences, teleconferences, monitored work, educational living experiences and cultural workshops. To evaluate the students' opinion about the course, a series of studies was carried out. This paper describes only the results drawn from two questionnaires, with closed questions, about the relationship the teacher-students established between their participation in the program, the occurrence of substantial improvements in their professional training and changes in their pedagogical practices in the classroom. This questionnaire was completed online and applied twice: at the beginning and at the end of the Program. The data was submitted to
\end{abstract}


various statistical processing techniques so as to yield a synthesis of information, identifying possible differences in opinion in relation to the aspects investigated, according to place of study and university. The results have shown that the main benefits gained from the program were, according to the teachers, the opportunity to reflect about the teaching profession, the theoretical basis they acquired and a better understanding of the teachinglearning process. Criticism was mainly directed at the time the students, who worked both shifts, had to comply with their reading and study; the insufficient skills the tutor had to advise them, and the complexity of the written texts, which made it quite difficult to understand the topics discussed. It seems necessary to improve these aspects for the Program's objectives to be reached, thus, meeting the expectations created.

Key-words: higher education, course evaluation, interactive media. 
Este artigo tem como objetivo descrever a avaliação de professores de ensino fundamental (com habilitação em nível médio) acerca de um curso de formação superior, em nível de licenciatura, até então inédito no país. Ele encontra-se estruturado da seguinte forma: situa-se, inicialmente, o contexto no qual o curso foi criado, bem como seu público-alvo, principais objetivos, currículo e método adotado. Em seguida, descrevemse os instrumentos utilizados para avaliar a opinião dos alunos-professores a respeito do curso que freqüentaram e a forma como os dados coletados foram tratados. Finalmente, os resultados são apresentados, e apontadas as principais conclusões a que se chegou, para que iniciativas similares futuras possam ser aprimoradas.

\section{O CONTEXTO DO PROGRAMA DE EDUCAÇÃO CONTINUADA/ FORMAÇÃO UNIVERSITÁRIA (PEC/FU)}

O Governo do Estado de São Paulo tem, desde 1995, procurado implementar mudanças substanciais no sistema educacional paulista. Para tanto, concentrou sua atuação em três eixos tidos como centrais: a racionalização organizacional, a mudança dos padrões de gestão escolar e a melhoria da qualidade do ensino. No que concerne ao último aspecto, buscou, em especial, a valorização dos profissionais do ensino e a formação dos quadros do magistério, com ênfase na formação continuada de seus especialistas e docentes.

Foi instituído, então, o PEC/FU cuja principal meta era a de oferecer formação superior, em nível de licenciatura, aos professores de ensino fundamental que possuíam apenas habilitação em nível médio. Ao agir assim, o governo do Estado atendia, ainda, ao que requer a Lei de Diretrizes e Bases da Educação Nacional (Lei n. 9394/96), que aponta a necessidade de os professores, que lecionam no ciclo inicial do ensino fundamental, terem formação superior. O Programa tinha, também, outros objetivos mais específicos:

- "habilitar os professores efetivos, visando a melhoria de sua atuação na rede estadual de ensino;

- possibilitar a experimentação e a avaliação, pela comunidade acadêmica paulista, de uma proposta não convencional de formação de professores, mediante mídias interativas, organizadas e monitoradas pela Secretaria de Estado da Educação e pelas Universidades e/ou Instituições de Ensino Superior paulistas; 
- ampliar as referências teórico-conceituais para uma melhor compreensão e descoberta de conteúdos e formas pedagógicas menos convencionais, possibilitando a produção e criação de opções mais significativas de aprendizagens dentro do coletivo das escolas, especialmente dos Centros Específicos de Formação e Aperfeiçoamento do Magistério (Cefams) como parte de uma rede integrada de geração de conhecimento no Estado².

Para que essas metas fossem atingidas, foram convidadas três universidades paulistas - USP, Unesp e PUC-SP - para elaborar e desenvolver um programa comum de formação de professores que utilizasse tecnologias inovadoras, e que eles não precisassem se deslocar muito de seus locais de moradia e de atuação profissional. Dos 39.100 docentes do primeiro ciclo do ensino básico, 12.400 tinham formação em nível médio. Optaram por participar do PEC/FU 7.500 docentes, uma vez que os demais estavam prestes a se aposentar ou afastados do trabalho, ou, ainda, já cursavam outra universidade.

O curso foi desenvolvido em 34 ambientes de aprendizagem, distribuídos ao longo do Estado. A carga horária total, de acordo com os termos da lei, foi de 3.100 horas, assim distribuídas:

- 1.600 horas de aulas;

- 400 horas de atividades complementares que deveriam resultar em trabalhos individuais, relacionando teoria e prática escolares no ensino;

- 300 horas, no mínimo, de prática de ensino, em tarefas dedicadas à recuperação de alunos, e a outras tidas como especiais;

- 800 horas, no máximo, segundo avaliação do aluno na sua experiência prévia na docência.

A proposta pedagógica envolvia um módulo introdutório (voltado para a capacitação dos alunos-professores em informática) e outros quatro dedicados à formação específica, os quais, integrados a vivências práticas, abordavam, respectivamente, os seguintes tópicos:

\footnotetext{
${ }^{2}$ Maiores informações podem ser encontradas em: <http://www.pec.sp.gov.br/abertura.html $>$.
} 
1) A dimensão experiencial, reflexiva e ética do trabalho docente

- a identidade profissional do professor, o contexto da formação continuada na experiência do $\mathrm{PEC} / \mathrm{FU}$ e sua concepção educacional;

- a educação continuada e o processo de construção da identidade profissional do professor;

- o contexto da formação/atuação profissional: primeiro levantamento diagnóstico dos alunos, das famílias e das comunidades;

- fundamentos da prática educativa.

2) A formação para a docência escolar: cenário político-pedagógico atual, conteúdo e didática das áreas curriculares

- reforma educacional e mudanças curriculares;

- fundamentos da educação e da ação docente;

- fundamentos históricos e sociais

- fundamentos psico-pedagógicos

- fundamentos da organização escolar;

- alfabetização;

- língua portuguesa;

- matemática;

- natureza, ciências, meio ambiente e saúde;

- espaço, tempo e cultura: história, geografia, ética e diversidade cultural;

- arte e educação;

- corpo, movimento, sexualidade e saúde.

3) Currículo: espaço e tempo de decisão coletiva

- o projeto educacional e a autonomia da escola;

- princípios de organização do currículo: contextualização e autonomia;

- currículo e avaliação do currículo.

4) Escola: um elo na rede da sociedade do conhecimento

- a internet como rede de conhecimento;

- a informática como suporte de aprendizagem;

- projeto de intervenção: ação local e comunicação global. 
Fica claro, portanto, que o PEC/FU preocupava-se em oferecer aos docentes uma formação que pudesse se articular à experiência que já tinham no magistério, imprimindo-lhe uma nova qualidade. A organização curricular deveria, dessa forma, garantir a ampliação e o aprofundamento dos conhecimentos sobre os conteúdos de ensino, a construção de competências e o uso de tecnologias avançadas em comunicação e informação.

Em termos de método, foram adotadas várias mídias interativas:

- videoconferências (2 ou 3 vezes por semana, com 4 horas de duração cada): aulas proferidas por professores, mestres ou doutores, indicados pelas diferentes universidades, de modo a fornecer o embasamento teórico-conceitual a cada tema em estudo. Alunos de diferentes salas podiam, caso quisessem, comunicar-se com o docente da universidade, ao vivo, bem como com os colegas das demais salas, de modo que poderia ser criada uma rede rica de interações;

- teleconferências (1 ou 2 vezes por mês, com 2 horas de duração cada): são transmitidas de um único ponto e são assistidas por todos os alunos, que têm possibilidade de interagir com os palestrantes pela internet, por fax ou telefone;

- trabalho monitorado (16 horas aproximadamente por semana): buscavam aprofundar e enriquecer os tópicos estudados nas aulas por videoconferência ou teleconferência e se voltavam, mais especificamente, para os trabalhos em sala de aula. Envolviam, assim, simulações da prática pedagógica, pesquisas, discussões e reflexões acerca das produções realizadas pelos discentes. Existiam três tipos de trabalhos monitorados:

- sessões on-line: os alunos interagiam, por meio da intranet, com professores-assistentes da universidade, para realizar determinadas atividades;

- sessões off-line: realizadas mediante o suporte do professor tutor, que era a pessoa que acompanhava cotidianamente a classe;

- sessões de suporte: nas quais os alunos podiam escolher a melhor forma de administrar seu tempo para seguir a programação proposta: se individualmente ou em grupo.

Houve, ainda, duas outras atividades:

- vivências educadoras (distribuídas pelos diferentes módulos, com carga horária variável, devendo, ao final, totalizar 700 horas): constituem momentos de ação e de reflexão prático- 
teóricas, realizadas ora em horário do curso, ora com a comunidade escolar (como prática de ensino), ou fora do tempo destinado ao curso. Por meio das vivências, buscava-se assegurar a articulação de referências teórico-conceituais e o dia-a-dia do professor, dentro e fora da sala de aula;

- oficinas culturais: tinham como objetivo ampliar o universo cultural dos alunos-professores, em especial no que dizia respeito aos diversos usos da leitura e da escrita e às diferentes manifestações artísticas (literatura, cinema, teatro, artes plásticas, fotografia e música), podendo, parte delas, recorrer à teleconferência ou videoconferência como suporte.

\section{INSTRUMENTOS UTILIZADOS PARA VERIFICAR A AVALIAÇÃO DOS DOCENTES ACERCA DO PEC/FU}

Para acompanhar as ações do PEC/FU, foi contratada uma equipe de avaliação externa que realizou uma série de investigações a respeito de aspectos tidos como centrais e inovadores do referido Programa. Descrevem-se, aqui, apenas os resultados obtidos por meio de dois opinionários, respondidos pelos alunos-professores sobre a participação no Programa; a ocorrência de melhorias em sua formação profissional; e mudanças em sua prática pedagógica em sala de aula. Esse instrumento, respondido on-line, foi coletado duas vezes: no início e ao final do PEC/FU, em dois dias consecutivos. Os dois instrumentos reuniam, no total, 56 afirmações fechadas ( 30 no primeiro e 26 no segundo) que abordavam dois conjuntos de itens: o primeiro, com afirmativas de natureza mais ampla, tinha a finalidade de averiguar qual era a percepção dos alunos-professores a respeito de sua participação em um Programa de Educação Continuada com as características do PEC/FU. O segundo possuía um número maior de afirmativas que focalizavam detalhes voltados às características gerais de organização do Programa. Para registrar suas respostas, foi construída uma escala de opinião mediante a qual os alunos-professores deveriam selecionar, no intervalo de 1 ("discordo totalmente") a 10 ("concordo totalmente"), o seu grau de concordância com a afirmação proposta no enunciado do item.

As respostas dadas aos instrumentos foram organizadas em um banco de dados, no qual cada registro reunia as seguintes informações: 
identificação do aluno-professor ${ }^{3}$, código da turma, período e Cefam em que o aluno-professor estava matriculado e o vetor de respostas associadas a cada questão fechada.

Organizadas as bases, foi adotado o seguinte procedimento: procedeu-se a uma tabulação geral dos dados com o objetivo de verificar, para cada conjunto de questões, qual a distribuição da freqüência de respostas em cada um dos pontos da escala de opinião. Constatada uma amplitude adequada na variação das respostas obtidas, realizou-se uma série de processamentos para obter uma síntese das informações e identificar eventuais diferenças de opiniões, tanto em relação aos aspectos investigados como entre os grupos de alunos-professores matriculados nas diferentes universidades e/ou Cefams. Os resultados obtidos em cada uma das etapas de análise são apresentados a seguir.

\section{Análise das respostas dadas ao primeiro opinionário}

O primeiro opinionário foi respondido por 4.478 participantes, número que correspondia a $71,84 \%$ do total de inscritos no Programa, como pode ser observado na Tabela 1.

Tabela 1 - Distribuição do número matrículas e de respostas dadas ao opinionário, segundo a universidade

\begin{tabular}{l|c|c|c|c}
\hline \multirow{2}{*}{ Universidade } & \multicolumn{2}{|c|}{ Número de matrículas } & \multicolumn{2}{c}{$\begin{array}{c}\text { Respostas ao primeiro } \\
\text { opinionário }\end{array}$} \\
\cline { 2 - 5 } & $\mathrm{N}$ & $\%$ & $\mathrm{~N}$ & $\%$ \\
\hline PUC & 1.446 & 23,2 & 964 & 21,5 \\
\hline Unesp & 3.133 & 50,3 & 2.441 & 54,5 \\
\hline USP & 1.654 & 26,5 & 1073 & 24,0 \\
\hline Total & 6.233 & 100,0 & 4.478 & 100,0 \\
\hline
\end{tabular}

Os dados da tabela indicam que, proporcionalmente ao total de matrículas, houve maior porcentual de respostas entre os participantes da Unesp (77,91\% dos alunos-professores emitiram suas opiniões), seguindo-

3 Por solicitação da equipe de avaliação, a identificação dos participantes foi feita apenas por meio de um código. Isso significa que nenhum dos alunos-professores foi identificado nominalmente. 
se, em termos de participação, os alunos-professores da PUC (66,67\%), e o menor volume de respostas foi registrado entre os estudantes da USP (64,87\%). Deve-se destacar também que, acompanhando a distribuição das matrículas, o maior porcentual de respostas corresponde aos participantes que realizaram o curso no período noturno, como se pode constatar pelos dados da Tabela 2.

Tabela 2 - Distribuição do número de respostas dadas ao opinionário, segundo a universidade e o período

\begin{tabular}{l|c|c|c|c}
\hline \multirow{2}{*}{ Universidade } & \multicolumn{3}{|c|}{ Período } & \multirow{2}{*}{ Total } \\
\cline { 2 - 4 } & Manhã & Tarde & Noite & \\
\hline PUC & 167 & 364 & 433 & 964 \\
\hline Unesp & 300 & 670 & 1.471 & 2.441 \\
\hline USP & 157 & 374 & 542 & 1.073 \\
\hline Total & 624 & 1.408 & 2.446 & 4.478 \\
\hline$\%$ & 13,9 & 31,4 & 54,6 & 100,0 \\
\hline
\end{tabular}

\section{$>$ Variações de opinião com relação aos aspectos investigados}

Ao iniciar esta análise, deve-se ressaltar o fato de que o porcentual de respostas nos pontos 9 e 10 da escala é elevado, indicando a presença de opiniões muito favoráveis na maior parte dos aspectos focalizados. No entanto, um estudo mais cuidadoso revela que existem variações na avaliação dos alunos-professores quando se passa de um subconjunto de itens a outro, o mesmo ocorrendo quando se examinam as respostas dadas aos itens de um mesmo agrupamento. A apresentação dos resultados procura evidenciar esses dados.

\section{$>$ Mudanças percebidas}

Inegavelmente, todos os alunos-professores foram, de algum modo, afetados pelo PEC/FU, uma vez que vivenciaram alguma modalidade de confrontação de seus valores e atitudes na e pela apropriação de novos conhecimentos. Depoimentos colhidos no decorrer do trabalho de campo já tinham apontado que, para os alunos-professores, a maior contribuição do PEC/FU tinha sido propiciar uma mudança na visão da prática docente, que se tornara mais crítica. No dizer dos alunos-professores, o 
esclarecimento teórico sobre a prática pedagógica e, sobretudo, um maior conhecimento sobre o processo de aprendizagem das crianças conferia maior segurança ao agir e, por esse motivo, eram considerados os principais aspectos positivos do Programa.

Tais impressões, recolhidas das entrevistas realizadas com uma pequena amostra de professores ${ }^{4}$, foram confirmadas quando se analisaram as respostas dadas pelo conjunto dos participantes aos itens do opinionário. No primeiro bloco de questões (no qual, conforme mencionado, se buscava identificar o grau de concordância dos participantes a respeito de afirmativas que estabeleciam uma relação de causa e efeito entre a participação no Programa e a ocorrência de melhorias relativas ao aprimoramento da formação profissional e/ou a mudanças nas práticas pedagógicas), porcentuais superiores a $60 \%$ nos pontos 9 e 10 da escala de opinião foram obtidos exatamente naqueles itens em que as afirmativas propostas destacavam, como principais contribuições do Programa, a oportunidade de reflexão a respeito da profissão docente, os benefícios da fundamentação teórica adquirida e a maior compreensão sobre o desenvolvimento do processo de aprendizagem. Esses resultados aparecem sintetizados na Tabela 3.

Tabela 3 - Porcentagem de respostas nos pontos 9 e 10 da escala de opiniões - Itens relativos às mudanças percebidas

\begin{tabular}{|c|c|}
\hline Afirmativas: $\mathrm{O}$ PEC/FU ... & $\%$ \\
\hline $\begin{array}{l}\text { Item 4. criou inúmeras oportunidades para que os professores pudessem refletir sobre suas } \\
\text { práticas de ensino. }\end{array}$ & 76,35 \\
\hline Item 1. contribuiu para o aprimoramento do meu trabalho como professora. & 73,04 \\
\hline Item 3. ampliou minha visão a respeito da profissão docente. & 69,11 \\
\hline $\begin{array}{l}\text { Item 5. mostrou-me que dominar os fundamentos teóricos que norteiam a prática de ensino é } \\
\text { indispensável para a melhoria da qualidade do ensino. }\end{array}$ & 65,90 \\
\hline $\begin{array}{l}\text { Item 26. contribuiu para que eu compreendesse melhor os processos de aprendizagem de meus } \\
\text { alunos. }\end{array}$ & 62,70 \\
\hline Item 7. levou-me, após ter dele participado, a elaborar textos com maior desenvoltura. & 59,86 \\
\hline $\begin{array}{l}\text { Item 6. mostrou-me ser fundamental que se tenha um certo tempo para refletir e assimilar } \\
\text { novas propostas, antes de conseguir modificar as práticas de ensino. }\end{array}$ & 58,14 \\
\hline Item 27. contribuiu para modificar meu relacionamento com os meus alunos. & 50,25 \\
\hline Item 2. não é condição suficiente para transformar a prática docente. & 18,73 \\
\hline
\end{tabular}

4 No estudo de caso, 36 alunos, sendo seis de cada Cefam, foram acompanhados mais de perto. 
Como se observa, há, de um item a outro, uma sensível graduação na freqüência de atribuição das "notas" mais altas, o que indica que o instrumento foi respondido adequadamente pelos participantes, e que os resultados servem para expressar, de maneira sintética, as diferenças de opiniões existentes no grupo investigado. Analisando os dados da Tabela 3, parece importante chamar a atenção, ainda, para:

- o expressivo grau de concordância atribuído pelos participantes às afirmativas propostas nos itens 7 ("...passei a elaborar textos com maior desenvoltura") e 6 ("a assimilação de novas propostas pedagógicas demanda um certo tempo");

- o fato de que mudanças no relacionamento com os alunos (item 27) foram apontadas pela metade dos alunos-professores nos pontos 9 e 10, seguidos de 27,38\% nos pontos 7 e 8, sugere o reconhecimento de algum impacto do PEC/FU no âmbito das relações interpessoais, em alguns casos até maior do que a sua influência em áreas que não se enquadram no domínio afetivo;

- as estatísticas calculadas com as notas atribuídas ao item 2 mostram que o valor da mediana foi igual a 6, indicando que pouco mais da metade dos alunos-professores tendeu a concordar com a afirmativa e pouco menos da metade dela discordou, considerando, portanto, que a participação em um Programa de Formação Continuada pode, sim, ser condição suficiente para transformar a prática docente.

\section{$>$ Opiniões sobre características gerais da organização do Programa}

Nesse bloco, foram reunidas quatro afirmativas que procuravam apreender a opinião dos alunos-professores a respeito dos seguintes aspectos: carga horária do Programa; volume de leituras exigido durante o curso; percepção dos participantes a respeito da necessidade de um professor presencial durante o curso, e, por último, a avaliação sobre o grau de participação que tiveram em decisões que afetavam o andamento dos trabalhos. Os porcentuais de respostas nos pontos 9 e 10 da escala de opinião são apresentados na Tabela 4. 
Tabela 4 - Porcentagem de respostas nos pontos 9 e 10 da escala de opiniões - Itens relativos às características de organização do Programa

\begin{tabular}{c|c}
\hline \multicolumn{1}{c|}{ Afirmativas } & $\%$ \\
\hline Item 11. A leitura dos textos seria mais bem aproveitada se \\
tivéssemos menos conteúdo e mais tempo. & 52,70 \\
\hline Item $\begin{array}{l}\text { 8. Um Programa destinado a profissionais em exercício } \\
\text { deveria ter uma carga horária mais flexível. }\end{array}$ & 48,89 \\
\hline Item 12. $\begin{array}{l}\text { Muitas decisões sobre o andamento dos trabalhos foram } \\
\text { tomadas sem que os principais interessados fossem } \\
\text { consultados. }\end{array}$ & 32,01 \\
\hline Item 20. A falta de um professor na sala de aula dificultou meu \\
aprendizado.
\end{tabular}

Dados de entrevistas indicaram que os alunos-professores, em alguns momentos, conseguiam encarar o PEC/FU como uma oportunidade efetiva de aprendizagem e desenvolvimento e, em outros, diante das inúmeras dificuldades impostas pela vida e pelo próprio curso, mostravam certo desânimo e questionavam o esforço despendido. Muitos se mostravam incomodados por não conseguirem gerir o tempo de forma eficaz, ressaltando como principal dificuldade a impossibilidade de conciliar o volume do conteúdo e a dinâmica do cronograma, ainda que alterações tenham sido efetuadas para permitir a revisão do conteúdo ou a realização de atividades que, por uma ou outra razão, não puderam ser feitas conforme inicialmente programado.

Analisando as respostas dadas pelos participantes aos itens 8 e 11 do opinionário, constata-se a alta freqüência de indivíduos que assinalaram os pontos 7, 8, 9 e 10 (78,17\% e 77,68\%, respectivamente), o que indica que a maioria manifestou alto grau de concordância com o enunciado das questões, e reafirma a necessidade de ajustes no cronograma em futuras edições do Programa, para que os participantes que, em geral, acumulam dupla jornada de trabalho, tenham mais tempo disponível para leituras e estudos. Opiniões mais diversificadas foram obtidas em resposta aos itens 12 e 20 desse bloco, como pode ser visto no Gráfico 1. 


\section{Gráfico 1 - Distribuição porcentual das respostas aos itens 12 e 20 do opinionário}

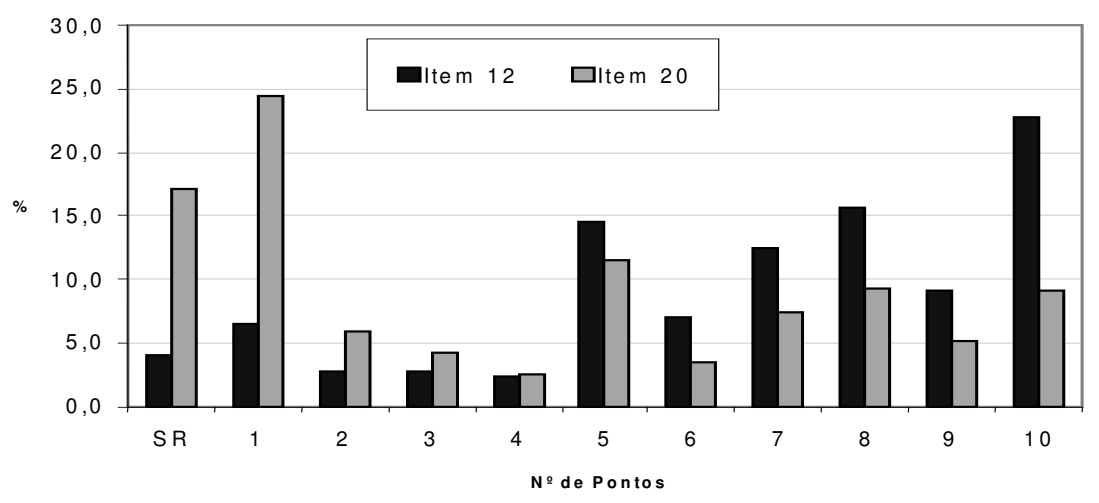

Os dados relativos à questão 12 indicam que a maior parte dos participantes concordou com o fato de que muitas decisões sobre o andamento dos trabalhos foram tomadas sem que eles tivessem sido consultados, algo talvez inevitável em razão das características peculiares do Programa. Em contrapartida, as respostas dadas à questão 20 mostram que a maioria considera que a ausência de um professor na sala de aula não dificulta o aprendizado dos alunos. Esse resultado, em certa medida, contraria depoimentos colhidos durante o trabalho de campo, bem como as opiniões manifestadas em outros itens do opinionário (como será visto mais adiante). Deve-se ressaltar, no entanto, que, quando se aborda a sistemática de organização de cursos com componentes a distância, um aspecto que costuma gerar divergências entre os participantes é a ausência de um professor nas salas de aula. Quiçá isso explique o fato de aproximadamente $20 \%$ deles terem deixado esse item sem resposta.

\section{$>$ Opiniões sobre a atuação e o papel dos tutores}

Quatro afirmativas foram agrupadas nesse bloco (itens 13, 19, 21 e 28), e os resultados obtidos na tabulação desse conjunto de respostas são comentados a seguir. A afirmativa 13 - "Várias atividades programadas não foram realizadas por falta de firmeza por parte do(a) tutor(a)" concentrou $43,68 \%$ das respostas, no intervalo compreendendo os pontos 1 
a 4, indicando que parte significativa dos alunos-professores discordava, total ou parcialmente, de seu enunciado. Cerca de $25 \%$ dos alunosprofessores, apontaram concordar, parcial ou plenamente, com a asserção observando-se, ainda, que 19,20\% deixaram a questão sem resposta e $12,28 \%$ assinalaram os pontos centrais da escala, manifestando dúvidas sobre como se posicionar a respeito do que estava sendo proposto.

Tendência semelhante de respostas foi observada no item 19 - "O tratamento que os diferentes temas receberam na sala de aula do PEC/FU foi inadequado". Assim, discordaram, total ou parcialmente, do enunciado da questão $51,42 \%$ dos participantes; concordaram, total ou plenamente, com a afirmativa $18,65 \%$ dos respondentes. Entre os demais, 16,07\% não responderam e 13,86\% escolheram selecionar os pontos "neutros" da escala.

Observa-se na afirmativa do item 21 - "Os tutores deveriam ser mais bem preparados para auxiliar os alunos-professores" - maior dispersão das respostas. Os que assinalaram os pontos 7 e 8 , indicando concordar parcialmente com a asserção, correspondem a $17,71 \%$. Os pontos 9 e 10 foram marcados por $23,83 \%$ dos alunos-professores, de modo que, ao se somar as respostas obtidas nos pontos 7 a 10 , alcança-se $41,54 \%$ de concordância com a asserção feita. Por outro lado, verifica-se que 6,80\% dos alunos-professores discordaram parcialmente da afirmativa (pontos 3 e 4), enquanto $24,59 \%$ discordaram totalmente (pontos 1 e 2). Escolheram não se manifestar $13,44 \%$ daqueles que responderam ao opinionário. Fica claro, portanto, que na percepção da maior parte dos participantes o grau de preparo dos tutores, para auxiliar os alunos, foi considerado insuficiente.

Opinião bem mais favorável à atuação dos tutores foi obtida em resposta à questão 28 - "O incentivo que recebi do(a) tutor(a) foi fundamental para que não abandonasse o curso". Concordaram com a afirmativa 70,67\% dos respondentes, e, dentre eles, a maioria $(53,24 \%)$ assinalou os pontos mais altos da escala. Os que discordaram (pontos 1 a 4), ou preferiram posicionar-se de forma imparcial (pontos 5 e 6), distribuíram-se quase que igualmente (13,15\% e $12,14 \%$, respectivamente). Uma síntese dos resultados apurados no conjunto de itens relativos à atuação e papel dos tutores é apresentada no Gráfico 2. 


\section{Gráfico 2 - Distribuição porcentual de respostas em diferentes pontos da escala de opiniões - Itens relativos à atuação dos tutores}

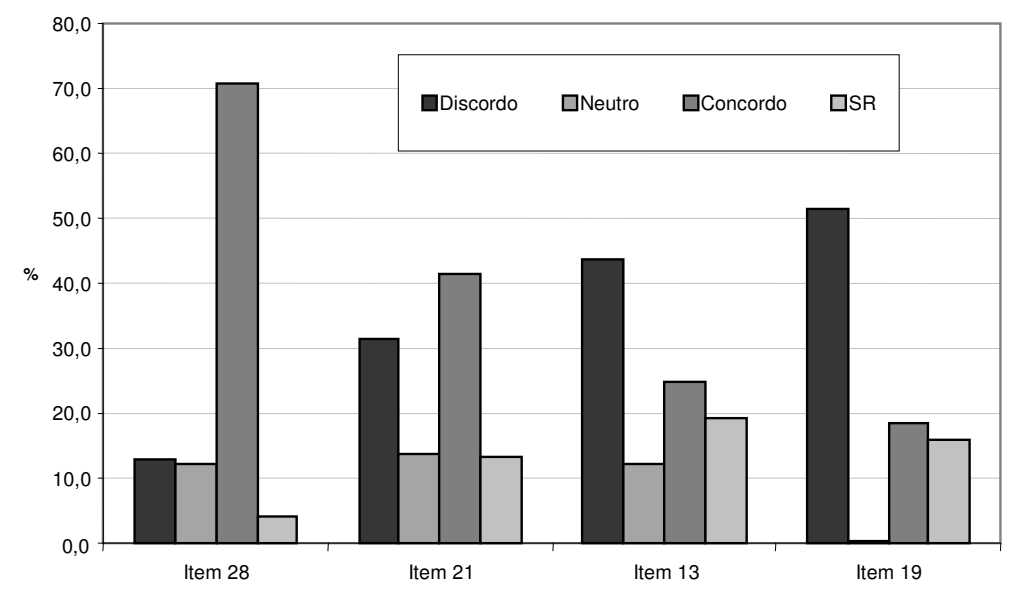

\section{$>$ Opiniões relativas ao material impresso}

Quatro questões foram elaboradas para colher as opiniões dos alunos-professores sobre o material impresso (itens 14, 17, 18 e 23). Nesse bloco, o item 18 - "Os diferentes temas apresentados no material impresso foram abordados de forma muito adequada" - foi o que reuniu as avaliações mais favoráveis: $82,41 \%$ de concordância, e, dentre os respondentes, a maior parte $(45,66 \%)$ assinalou os pontos mais altos da escala. Desse modo, fica claro que, para a maioria, a abordagem dos temas selecionados para constituir o material impresso foi adequada.

No entanto, quando se solicitou que assinalassem seu grau de concordância com o proposto na questão 23 - "Se os textos fossem menos complexos, meu aproveitamento seria melhor" - obteve-se um porcentual de respostas também expressivo nos pontos mais altos da escala (7 a 10), indicando que, para uma parcela significativa dos alunos-professores $(45,77 \%)$, a complexidade dos textos foi um fator que dificultou um melhor aproveitamento.

A análise das respostas dadas às duas outras afirmativas - item 14, "O material impresso foi muito bem formulado, mas as situações retratadas não fazem parte da realidade da nossa escola", e item 17, "Fiquei frustrado(a) por não ter compreendido alguns assuntos importantes" revela resultados muito próximos, ocorrendo nos dois itens uma clara 
divisão nas avaliações feitas pelos participantes. Assim, concordaram parcial ou plenamente com as duas asserções pouco mais de $1 / 3$ dos respondentes (36,52\% no item 14 e $35,79 \%$ no 17$)$. Grupos igualmente significativos assinalaram respostas que sinalizavam sua discordância parcial ou total com os enunciados: $33,65 \%$ e 35,76\% (itens 14 e 17, respectivamente). Decidiram não se manifestar, assinalando os pontos 5 e 6 da escala de opiniões, $21,44 \%$ (item 14) e 18,86\% (item 17) dos alunosprofessores. Uma síntese das opiniões emitidas sobre o material impresso é apresentada no Gráfico 3.

\section{Gráfico 3 - Distribuição porcentual de respostas em diferentes pontos da escala de opiniões - Itens relativos ao material impresso}

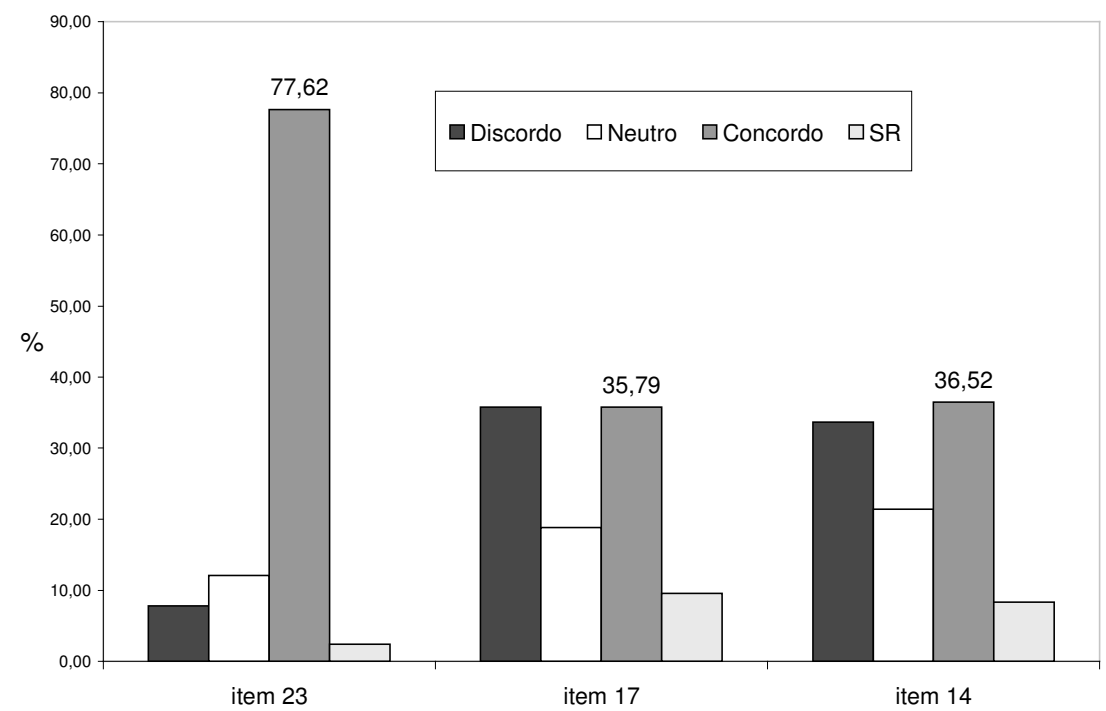

\section{$>$ Opiniões relativas a algumas das atividades programadas}

Foram reunidos nesse bloco três itens, dos quais um tinha como foco as "Vivências Educadoras", e os outros dois o "Estágio Supervisionado". A afirmativa do item 15 - "As Vivências Educadoras serviram efetivamente para integrar teoria e prática" - obteve 54,96\% de respostas nos pontos 9 e 10, indicando que a maioria dos alunosprofessores concordava plenamente com ela. Em seguida, observa-se $29,88 \%$ de respostas nos pontos 7 e 8 , mostrando que outros $30 \%$ concordavam parcialmente com a asserção. Fica clara, desse modo, a 
importância atribuída pela maioria $(84,84 \%)$ dos alunos-professores às temáticas que se relacionam de perto com a prática docente.

Segue a mesma tendência da anterior a afirmativa do item 30 - "O estágio (suporte 2), mesmo para professores com experiência de ensino, é uma experiência que enriquece muito a prática pedagógica". Os resultados mostram que o ponto 10 foi o mais freqüentemente assinalado $(46,00 \%)$, e a somatória das respostas situadas nos pontos 7 a 10 perfaz um total de $81,40 \%$. Evidencia-se, portanto, que a maioria dos participantes considerou a realização dos estágios uma oportunidade de enriquecimento profissional.

Solicitados a indicar se o estágio deveria ser optativo para professores com experiência de ensino (item 29), obteve-se uma distribuição de respostas que indica opiniões heterogêneas a respeito do assunto, ainda que a maior parte tenha concordado com a afirmativa. Analisando a distribuição das respostas, verifica-se que não responderam à questão $7,92 \%$ dos sujeitos; preferiram omitir sua opinião, assinalando os pontos 5 e 6, outros 19,09\%; consideraram que o estágio deveria ser optativo $44,59 \%$ dos alunos-professores, e manifestaram opinião contrária a essa, outros $28,39 \%$.

\section{$>$ Opiniões relativas às avaliações realizadas durante o curso}

Duas questões foram elaboradas tendo por objetivo levantar a opinião dos alunos-professores acerca das avaliações conduzidas. Os resultados obtidos com a tabulação das respostas apontam tendência semelhante nas opiniões emitidas a respeito dos dois aspectos focalizados, como pode ser constatado pelos dados da Tabela 5.

Tabela 5 - Porcentagem por categoria de resposta - Itens relativos às características das avaliações conduzidas

\begin{tabular}{|c|c|c|c|c|c|}
\hline \multirow{2}{*}{ Afirmativas } & \multicolumn{5}{|c|}{ Categorias de resposta $(\%)$} \\
\hline & $\mathrm{S} / \mathrm{R}$ & 1 a 4 & 5 e 6 & 7 e 8 & 9 e 10 \\
\hline $\begin{array}{l}\text { Item 9. As avaliações (provas) realizadas } \\
\text { foram muito tradicionais. }\end{array}$ & 4,25 & 16,33 & 20,71 & 30,09 & 28,63 \\
\hline $\begin{array}{l}\text { Item 10. Os resultados da avaliação (notas) } \\
\text { nem sempre foram justos. }\end{array}$ & 6,85 & 23,94 & 15,79 & 26,44 & 26,99 \\
\hline
\end{tabular}


Os dados indicam que parcela significativa dos participantes (58,72\% no caso da afirmativa do item 9 , e $53,43 \%$ no caso da afirmativa do item 10) teceu críticas tanto ao formato das provas como aos resultados das avaliações.

\section{$>$ Opiniões relativas ao emprego de recursos tecnológicos}

Para verificar a opinião dos alunos-professores acerca do emprego de recursos tecnológicos, quatro questões foram elaboradas. De maneira geral, os resultados encontrados na Tabela 6 mostram respostas que indicam um nível elevado de aprovação, em especial na asserção 25 , em que $81,37 \%$ dos respondentes situam-se nos pontos que vão de 7 a 10 . No item 16, referente às videoconferências, cerca de 60\% dos alunosprofessores seguiram essa mesma tendência, ainda que o número daqueles que dela discordaram tenha sido bastante elevado. $\mathrm{O}$ menor porcentual de aprovação foi encontrado na afirmativa do item 24 (24,05\%), indicando que o PEC/FU não promoveu a desenvoltura desejada nos alunos-professores. Uma porcentagem elevada de sujeitos $(16,28 \%)$ deixou de responder à afirmativa do item 24, número que difere, em muito, do porcentual dos que se omitiram nas outras asserções que compunham esse bloco.

Tabela 6 - Porcentagem por categoria de resposta - Itens relativos ao emprego de recursos tecnológicos

\begin{tabular}{l|c|c|c|c|c}
\hline \multirow{2}{*}{ Afirmativas } & \multicolumn{4}{c}{ Categorias de resposta (\%) } \\
\cline { 2 - 6 } & S/R & $\mathbf{1 ~ a ~ 4}$ & $\mathbf{5}$ e 6 & $\mathbf{7 ~ e ~ 8}$ & $\mathbf{9}$ e 10 \\
\hline Item 16. $\begin{array}{l}\text { As videoconferências foram } \\
\text { fundamentais para que nossas } \\
\text { dúvidas pudessem ser esclarecidas }\end{array}$ & 2,03 & 11,46 & 26,52 & 34,96 & 25,03 \\
\hline $\begin{array}{l}\text { Mesmo após participar do } \\
\text { PEC/FU, não utilizo o } \\
\text { computador com maior } \\
\text { desenvoltura }\end{array}$ & 16,28 & 44,18 & 15,50 & 15,97 & 8,08 \\
\hline $\begin{array}{l}\text { Os recursos tecnológicos } \\
\text { utilizados no PEC/FU facilitaram } \\
\text { a apropriação dos conteúdos } \\
\text { tratados }\end{array}$ & 1,98 & 2,42 & 14,22 & 31,36 & 50,01 \\
\hline
\end{tabular}




\section{Análise das respostas dadas ao segundo opinionário}

Como já foi assinalado, esse instrumento era composto por 26 questões subdivididas em três blocos com características bem distintas. No primeiro deles, itens 1 a 6, solicitou-se aos participantes que manifestassem sua opinião a respeito de alguns aspectos do módulo 3, Tema 6 (Ciências) e Tema 7 (História e Geografia). No segundo conjunto de questões (itens 12 a 19), foi solicitado aos alunos-professores que avaliassem algumas das atividades (ou modalidades metodológicas) desenvolvidas durante o curso, e, no terceiro bloco (itens 20 a 26), que avaliassem os diferentes atores ou agentes responsáveis pela condução das atividades.

Os principais resultados obtidos com a tabulação das respostas dadas a esse segundo instrumento são apresentados a seguir.

\section{Opiniões sobre o Tema 6 - Ciências}

Predominam as avaliações mais favoráveis, sobretudo nos aspectos referentes à clareza da linguagem do material impresso e à profundidade com que os tópicos de Ciências foram desenvolvidos (itens 4 e 5), como se observa no Gráfico 4.

\section{Gráfico 4 - Porcentagem por categoria de resposta - Itens da área de Ciências}

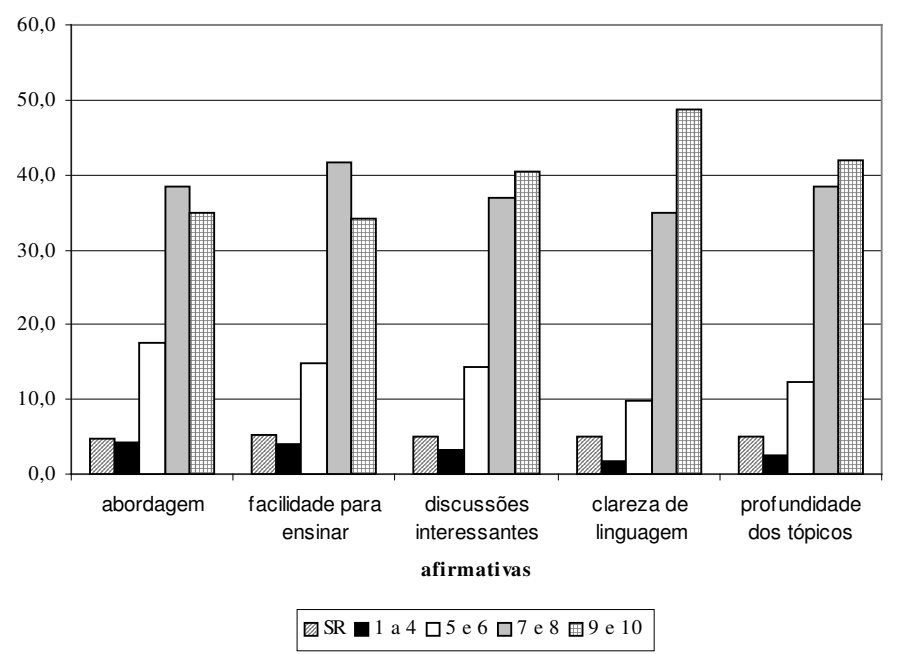




\section{Opiniões sobre o Tema 7 - História e Geografia}

$\mathrm{Na}$ avaliação dos materiais produzidos para o desenvolvimento deste tema, avaliações mais favoráveis foram registradas sobretudo em relação à adequação do tratamento dado aos conteúdos (item 10 profundidade com que os tópicos foram abordados). Também foram positivas as respostas dadas ao fato de $\mathrm{o}$ material $\mathrm{e}$ as aulas (videoconferências e teleconferências) terem proporcionado discussões interessantes (item 9). Uma síntese desses resultados é apresentada no Gráfico 5.

\section{Gráfico 5 - Porcentagem por categoria de resposta - Itens da área de História e Geografia}

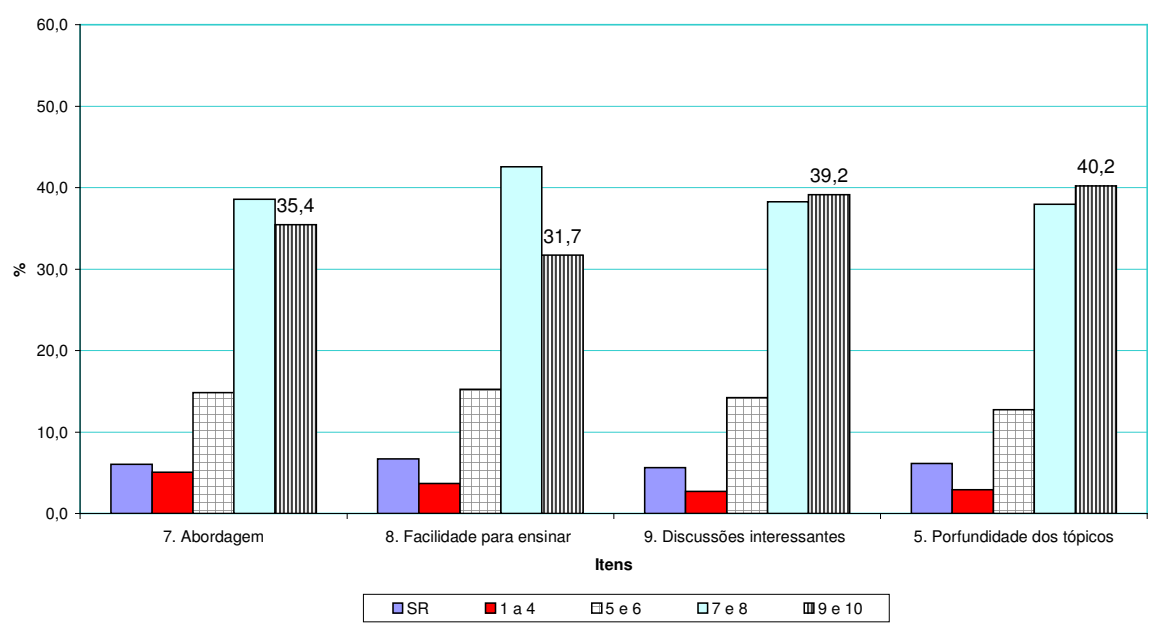

\section{Opiniões sobre as atividades}

No conjunto de itens relativos às atividades desenvolvidas pelo Programa (12 a 19), a elaboração da "Monografia" foi a que obteve maior porcentual de respostas nos pontos mais altos das escala, seguida pela atividade "Memórias". Índices sensivelmente mais baixos em termos de aprovação foram atribuídos, pelos participantes, às atividades envolvendo o Learning Space (atividades realizadas por meio do computador) e as "Videoconferências", como pode ser observado no Gráfico 6. 


\section{Gráfico 6 - Porcentagem por categoria de resposta - Itens relativos às atividades do PEC}

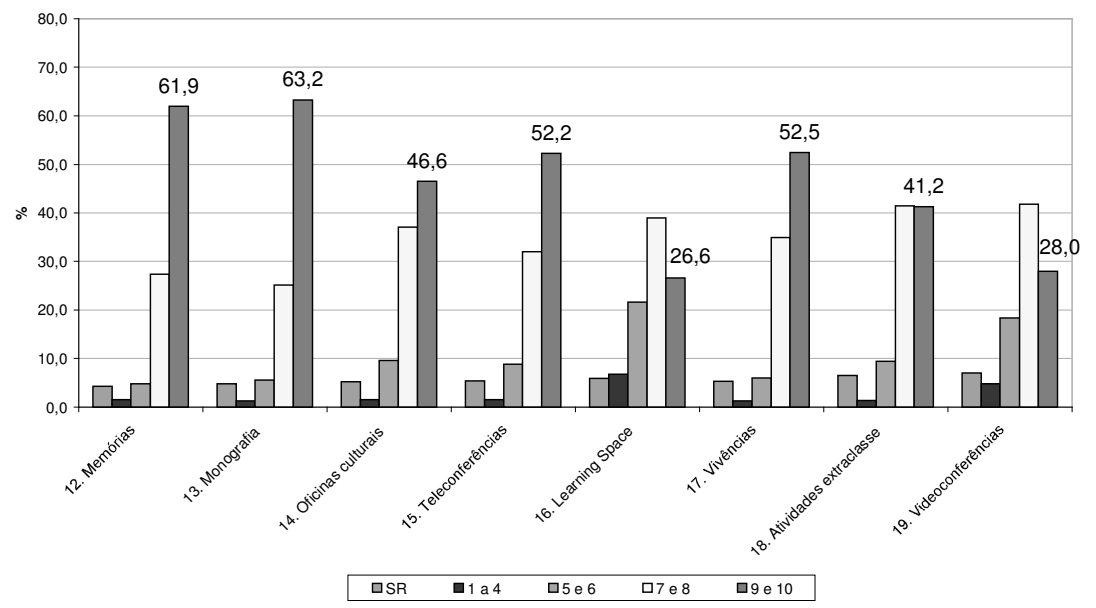

Nos itens finais do opinionário (21 a 26), solicitou-se que avaliassem a contribuição dos seguintes agentes: estagiários, tutores, professoresassistentes, professores-orientadores, equipe da universidade, equipe gestora do PEC e, por último, que realizassem uma auto-avaliação, atribuindo uma nota à própria participação.

É nesse conjunto de itens que aparecem as avaliações mais favoráveis, com especial destaque para a própria atuação dos alunosprofessores. Segue-se, pela ordem, com percentuais superiores a $60 \%$ nos pontos 9 e 10 da escala, a atuação dos tutores, da equipe da universidade e da equipe gestora do PEC/FU. Uma síntese desses resultados pode ser observada no Gráfico 7. 


\section{Gráfico 7 - Porcentagem por categoria de resposta - Itens relativos aos participantes}

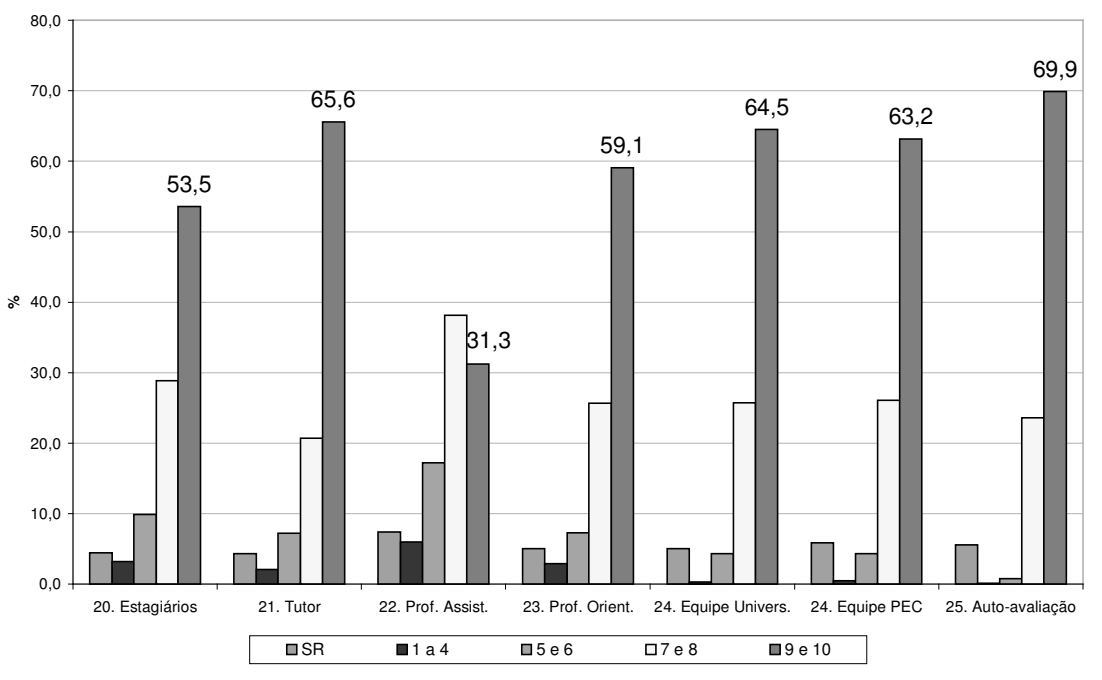

\section{CONCLUSÕES}

De modo geral, é possível afirmar que os alunos-professores manifestaram-se de maneira positiva quanto a diversos aspectos do Programa PEC/FU, uma vez que o percentual de respostas nos pontos superiores da escala de opiniões foi igual ou superior a $50 \%$. Adquirem, assim, especial destaque as afirmativas dos itens 4, 1, 3, 5 e 26, referentes ao item "Mudanças", destacando que os alunos-professores perceberam como centrais as seguintes contribuições do PEC/FU: a oportunidade de reflexão a respeito da profissão docente, os benefícios da fundamentação teórica adquirida e a maior compreensão sobre o desenvolvimento do processo de aprendizagem. Os itens 8 e 11 (referentes à organização do Programa) também alcançaram percentuais elevados (respectivamente, $78,17 \%$ e $77,68 \%$ ), salientando a necessidade de contemplar, de maneira mais apropriada, o tempo realmente disponível para leituras e estudos que os discentes, que mantêm dupla jornada de trabalho, possuem.

No que diz respeito à atuação dos tutores, pode-se dizer que, na percepção da maior parte dos participantes, o grau de preparo desses agentes educacionais foi considerado insuficiente para auxiliar os alunosprofessores (item 21). Por outro lado, o item 28 , que se referia ao incentivo recebido dos tutores para que não abandonassem o curso, recebeu um 
percentual elevado de respostas nos pontos mais altos da escala $(70 \%)$, indicativo de opinião favorável. Isso parece indicar que, na percepção dos alunos, o tutor, ainda que não tenha auxiliado na compreensão dos textos, é visto como um animador importante para seguir em frente.

No bloco concernente às opiniões acerca do material impresso, verifica-se que avaliação favorável foi encontrada no item 18 (82,41\% de concordância), indicando que os temas selecionados foram adequados para professores que lecionam nas séries iniciais. Por outro lado, a afirmativa do item 23 apontou que, para uma parcela importante do corpo discente $(45,77 \%)$, a complexidade dos textos dificultou sua leitura e compreensão, com prejuízo no aproveitamento do curso. Dessa forma, parece que na ausência de um tutor bem formado teoricamente, capaz de mediar as aprendizagens dos alunos, os temas tratados, ainda que pertinentes, precisariam ser apresentados de maneira mais didática e simples.

Já em relação ao emprego de recursos tecnológicos, destacam-se as asserções 25 e 16, pelo elevado percentual de aprovação nelas encontradas (81,37\% e $60 \%$, respectivamente), o que indica que recursos tecnológicos utilizados no PEC/FU facilitaram a apropriação dos conteúdos tratados e, ainda, que as videoconferências auxiliaram, em muito, o esclarecimento de dúvidas dos alunos-professores. Em contrapartida, os baixos percentuais encontrados no item 24 desse bloco $(24,05 \%)$ levam à conclusão de que não se alcançou a desenvoltura desejada por parte dos alunos-professores.

Dessa maneira, os pontos apontados pelos respondentes como negativos carecem de maior atenção em futuras iniciativas semelhantes. Aprimorar esses tópicos significa, antes de qualquer coisa, alcançar os objetivos traçados pelos que implementaram o PEC/FU e, sobretudo, atender às expectativas criadas naqueles que dele participaram.

Recebido em: maio 2007

Aprovado para publicação em: julho 2007 